\title{
Gas Chromatographic Determination of Organochlorines in Biota by Preliminary Fractionation on Conditioned Silica Gel Column.
}

\author{
JOHN SATSMADJIS* and BASIL IATRIDIS** \\ *Institute of Oceanographic and Fisheries Research, \\ GR-166 04 Hellinikon, Greece. \\ ** National Technical University of Athens, Patission 42, \\ GR-104 33, Athens, Greece. \\ (Received 2nd November, 1983)
}

\begin{abstract}
A complete method is described for the reliable determination in animal tissues of polychlorinated biphenyls (PCBs), aldrin, p, p'-DDE, heptachlor, o, $\mathrm{p}^{\prime}$-DDT, p, $\mathrm{p}^{\prime}$-DDT, $p, p^{\prime}-\mathrm{DDD}, \alpha$-BHC, $\gamma$-BHC (lindane), heptachlor epoxide, dieldrin and endrin. It aims at over coming a plethora of difficulties, the gravest of which deal with analytes loss and alteration, interference, identification, fouling of the column and the detector of the gas chromatograph, non-linear response of the latter and contamination. It comprises hexane extraction, removal of lipids on an alumina column, separation into six fractions on a silica gel column and injection into a gas chromatograph equipped with a ${ }^{63} \mathrm{Ni}$ electron capture detector. Special attention is paid to the conditioning of the silica gel column and the identification of all the peaks, including those of the PCBs.
\end{abstract}

\section{Introduction}

The estimation of chlorinated hydrocarbons in body tissues by gas chomatography constitutes a challenge to the chemist. This is because of the very low concentrations involved, the volatility and large number of constituents, the multitude and high concentrations of the interfering compounds and the disastrous effect of even traces of impurities on the column and the detector of the gas chromatograph. Usually, the 
treatment of the sample, prior to its processing on the gas chromatograph, comprises three major steps: solvent extraction of the organochlorines, removal of the majority of the coextractives and separation into some fractions by liquid chromatography. The second operation, because of its absolute necessity and great difficulty, has stimulated a great deal of research, leading to various techniques.

A popular technique relies on liquid-liquid partition. By shaking, the analytes are brought from hexane (or petroleum ether) into the more polar acetonitrile (or dimethylformamide); then, after dissolution of the latter into water, they are back extracted into hexane. This lengthy manipulation, besides failing to achieve complete recovery, is subject to contamination, consumes large amounts of very costly solvents and requires further treatment: drying, as well as passage through a column packed with either Florisil, silica gel, alumina, magnesia or celite, to eliminate the remaining fat and pigments.

A much simpler and cheaper clean-up procedure consists of shaking vigorously on a vibrator the hexane extract with a few drops of concentrated sulphuric acid. However, since this violent treatment spares only the PCBs, DDTs and lindane, it can be used solely for determining these compounds. Similarly, saponification with potassium hydroxide, though easy and efficient, has limited value. It does not alter the PCBs, but affects other analytes: thus, it dechlorinates, $p, p^{\prime}-D D T$ into $p, p^{\prime}$-DDE and $p, p^{\prime}-D D D$ into $\mathrm{p}, \mathrm{p}^{\prime}$-MDE.

An even more practical way of removing interfering substances involves liquid-solid chromatography. Holden and Marsden (1969) demonstrated the superiority of alumina over Florisil and silica gel. By elution with hexane, this material lets out every constituent of interest, while it absorbs nearly all the unwanted compounds. Note that the pretreatment of alumina at $800^{\circ} \mathrm{C}$ ensures its becoming absolutely free from any organic chemical. On the contrary, silica gel and Florisil deteriorate at the high temperatures needed to remove by heat the PCBs and other impurities they contain. Their adequate purification requires such an elaborate technique as to exclude their practical use. The above workers propounded also, as the next stage, the separation into two fractions, using a silica gel column and eluting first with hexane, then with $10 \%$ diethyleter in hexane.

\section{Preliminary Considerations}

\section{Separation on the gas chromatograph}

The investigation of the degree of separation of the analytes realised on the gas chromatograph requires knowing their retention times, $t$, and their peak widths at mid-height, $w$. Tables 1 and 2 list the values of $t$ and $w$ obtained with a Tracor 222 instrument equipped with a ${ }^{63} \mathrm{Ni}$ electron capture detector operating on 25-30 volt DC. The 6' x 14" glass column was packed with $3 \%$ OV-1 on chromosorb CW-HP 80/100 mesh. The nitrogen carrier gas had a flow rate of $65 \mathrm{ml} / \mathrm{min}$ in the column and 20 $\mathrm{ml} / \mathrm{min}$ in the direct line to the detector. The temperature was $200^{\circ} \mathrm{C}$ in the column and $250-260^{\circ} \mathrm{C}$ in the detector. The retention times, expressed in $\mathrm{mm}$ (with $12.7=1 \mathrm{~min}$.) are counted, for both theoretical and practical reasons, from the straight line produced by the arrival of the solvent peak, itself situated $3.3 \mathrm{~mm}$ beyond the injection point. The ratio, $r$, of the retention time, $t$, of the constituent to that, $t_{0}$, of p,p-DDT is also maintained, because it remains nearly constant in spite of any variation of the carrier gas flow rate and slight change of column temperature. 
Table 1 Percentage distribution of the analytes over the silica gel fractions.

Column dimensions: total length, $641 \mathrm{~mm}$; i.d., $4 \pm$ 0.2mm. Packing: material, BDH 60-120 mesh silica gel for chromatographic adsorption (product No 15049), with about $16 \%$ water added; length, 580-590mm; weight, 6-7 g. Eluents: hexane, 11-12 ml; 20\% ether in hexane, $20 \mathrm{ml}$.

\begin{tabular}{|c|c|c|c|c|c|c|c|c|c|}
\hline \multirow[t]{2}{*}{ Compound } & \multirow[t]{2}{*}{$\begin{array}{c}t\left({ }^{1}\right) \\
(\mathrm{mm})\end{array}$} & \multirow[t]{2}{*}{$\begin{array}{c}r\left({ }^{2}\right) \\
(\mathrm{mm})\end{array}$} & \multirow[t]{2}{*}{$\begin{array}{c}w\left(^{(3)}\right. \\
(\mathrm{mm})\end{array}$} & \multicolumn{4}{|c|}{$\begin{array}{l}\text { Hexane fractions } \\
(\mathrm{ml})\end{array}$} & \multicolumn{2}{|c|}{$\begin{array}{c}20 \% \text { ether in } \\
\text { hexane } \\
(\mathrm{ml})\end{array}$} \\
\hline & & & & $2.5-5$ & $5-6$ & $6-9$ & $9-14$ & & $24-34$ \\
\hline Aroclor 1254 & $25.5-167$ & $0.30-1.94$ & $2.3-9.8$ & 66.0 & 25.2 & 7.6 & 1.2 & & \\
\hline Aroclor 1260 & $37.5-259$ & $0.30-3.01$ & $3.1-15$ & 76.3 & 17.3 & 5.6 & 0.8 & & \\
\hline Aldrin & 30 & 0.35 & 2.3 & 76.2 & 15.0 & 6.9 & 1.9 & & \\
\hline $\mathrm{p}, \mathrm{p}^{\prime}-\mathrm{DDE}$ & 52.5 & 0.61 & 3.6 & 64.1 & 25.9 & 8.2 & 1.8 & & \\
\hline Heptachlor & 24 & 0.28 & 1.9 & 29.4 & 44.6 & 22.5 & 3.5 & & \\
\hline$o, p^{\prime}-\mathrm{DDT}$ & 70 & 0.81 & 4.5 & 14.1 & 38.1 & 42.5 & 5.3 & & \\
\hline$p, p^{\prime}-D D T$ & 86 & 1.00 & 5.1 & & 15.4 & 73.8 & 10.8 & & \\
\hline$p, p^{\prime}-D D D$ & 66 & 0.77 & 4.6 & & & & 70.6 & 26.6 & 2.8 \\
\hline $\mathrm{BHC}$ & 11.5 & 0.14 & 1.3 & & & & 17.5 & 80.9 & 1.6 \\
\hline BHC & 14.5 & 0.17 & 1.6 & & & & & 76.1 & 23.9 \\
\hline Heptachlor epox. & 37 & 0.43 & 2.5 & & & & & 79.4 & 20.6 \\
\hline Dieldrin & 53.5 & 0.62 & 3.5 & & & & & 81.1 & 18.9 \\
\hline Endrin & 59.5 & 0.69 & 3.8 & & & & & 72.8 & 27.2 \\
\hline Endrin & 68 & 0.79 & 4.7 & & & & & & \\
\hline Endrin & 100 & 1.16 & 5.9 & & & & & & \\
\hline
\end{tabular}

(1) retention time in the Tracor 222 gas chromatograph. Glass column: dimensions, 6 ' $x^{1 / 4}$ " i.d.; packing, $3 \%$ OV-1 in chromosorb CW-HP $80-100$ mesh; temperature, $200^{\circ} \mathrm{C}$; flowrate nitrogen carrier gas, $65 \mathrm{ml} / \mathrm{min} .{ }^{63} \mathrm{Ni}$ electron capture detector: electrodes, $25-30$ volt $\mathrm{DC}$; temperature, $250-260^{\circ} \mathrm{C}$; flowrate of nitrogen scavenger gas, $20 \mathrm{ml} / \mathrm{min}$.

(2) $t / t_{0}\left(t_{0}=t\right.$ of p, $^{\prime}$-DDT)

(3) peak width at mid-height

Two peaks become discernible when the difference between their retention times exceeds half the sum of their peak widths at mid-height $\left[t_{1}-t_{2}>\left(w_{1}+w_{2}\right) / 2\right]$; but a full separation demands double this amount $\left[t_{1}-t_{2}>w_{1}+w_{2}\right]$. It can be seen from Table 1 that even the simple constituents cause difficulty. Thus p, $\mathrm{p}^{\prime}$-DDE $(t=52.5, w=3.6)$ interferes with dieldrin $(53.5,3.5)$, and similarly endrin isomer $(68,4.7)$ with both p, $\mathrm{p}^{\prime}$ $\operatorname{DDD}(66,4.6)$ and o,p'-DDT $(70,4.5)$. Also $\alpha$-BHC $(11.5,1.3)$ is not completely separated from $\gamma$-BHC $(14.5,1.6)$, nor endrin $(59.5,3.8)$ from both dieldrin $(53.5,3.5)$ and p,p'-DDD $(66,4.6)$.

As actual samples often contain many more chlorinated hydrocarbons, in relatively large amounts, a great confusion may occur. Aroclors 1254 and 1260 alone furnish 20 distinct peaks (see Table 2). In addition, in most cases, the peaks correspond to at least two chemicals, even when their widths at mid-height (not reported) seem normal, since the minor components, having retention times close to that of a major peak, broaden only the base of it. Furthermore, Aroclors 1242 and 1248 give peaks which interfere with those of the BHC's. 
Table 2 Percentage Distribution of the Discernible Components of Aroclors 1254 and 1260 over the Silica Gel Fractions.

\begin{tabular}{|c|c|c|c|c|c|c|}
\hline Component & $\begin{array}{c}t\left({ }^{1}\right) \\
(\mathrm{mm})\end{array}$ & $r\left({ }^{2}\right)$ & $\begin{array}{c}2.5-5 \\
(\mathrm{ml})\end{array}$ & $\begin{array}{c}5-6 \\
(\mathrm{ml})\end{array}$ & $\begin{array}{c}6-9 \\
(\mathrm{ml})\end{array}$ & $\begin{array}{l}9-14 \\
(\mathrm{ml})\end{array}$ \\
\hline 1 & $25.5\left(^{3}\right)$ & 0.30 & 40 & 35 & 20 & 5 \\
\hline 2 & $29 \quad\left(^{3}\right)$ & 0.34 & 25 & 40 & 25 & 10 \\
\hline 3 & $31 \quad\left({ }^{3}\right)$ & 0.36 & 30 & 40 & 30 & 0 \\
\hline 4 & 37 & 0.43 & 42 & 37 & 18 & 3 \\
\hline 5 & 44.5 & 0.52 & 88 & 9 & 3 & 0 \\
\hline 6 & $52.5\left(^{3}\right)$ & 0.61 & 66 & 29 & 5 & 0 \\
\hline 7 & 55 & 0.64 & 52 & 36 & 10 & 2 \\
\hline 8 & $62 \quad\left(^{4}\right)$ & 0.72 & 88 & 10 & 2 & 0 \\
\hline 9 & 65.5 & 0.76 & 90 & 10 & 0 & 0 \\
\hline 10 & 76 & 0.88 & 72 & 21 & 7 & 0 \\
\hline 11 & 83 & 0.97 & 90 & 10 & 0 & 0 \\
\hline 12 & 90 & 1.05 & 86 & 14 & 0 & 0 \\
\hline 13 & 104.5 & 1.22 & 40 & 35 & 20 & 5 \\
\hline 14 & $115 \quad\left({ }^{4}\right)$ & 1.34 & 50 & 45 & 5 & 0 \\
\hline 15 & 124 & 1.44 & 85 & 15 & 0 & 0 \\
\hline 16 & 142 & 1.65 & 100 & 0 & 0 & 0 \\
\hline 17 & 167 & 1.94 & 60 & 40 & 0 & 0 \\
\hline 18 & $188 \quad\left({ }^{4}\right)$ & 2.19 & 95 & 5 & 0 & 0 \\
\hline 19 & $223 \quad\left({ }^{4}\right)$ & 2.59 & 70 & 30 & 0 & 0 \\
\hline 20 & $259 \quad\left({ }^{4}\right)$ & 3.01 & 95 & 5 & 0 & 0 \\
\hline
\end{tabular}

(1) retention time in the Tracor 222 gas chromatograph. Glass column: dimensions, 6 ' $\mathrm{x}^{1 / 1}$ " 'i.d.; packing, $3 \% \mathrm{OV}-1$ in chromosorb CW-HP $80 / 100$ mesh; temperature, $200^{\circ} \mathrm{C}$; flowrate nitrogen carrier gas, $65 \mathrm{ml} / \mathrm{min} .{ }^{63} \mathrm{Ni}$ electron capture detector: electrodes, $25-30$ volt $\mathrm{DC}$; temperature, $250-260^{\circ} \mathrm{C}$; flowrate of nitrogen scavenger gas, $20 \mathrm{ml} / \mathrm{min}$.

(2) $t / t_{0}\left(t_{0}=t\right.$ of $\mathbf{p}, \mathbf{p}^{\prime}$-DDT $)$

(3) in Aroclor 1254 only

(4) in Aroclor 1260 only

In conclusion, the determination of organochlorines in animal tissues requires the separation of the sample extract into fractions prior to its injection into the gas chromatograph. The use in this instrument of at least two columns with different packings, recommended by Holden (1973), assists in the identification of the peaks, but does not reduce the congestion on the chromatograms.

\section{Separation on the silica gel column.}

The procedure described later comprises the elution of the sample extract on a silica gel column. Tables 1 and 2 indicate, for each constituent, the amount, relative to the total, present in the six collected fractions. The values shown are the means of a large number of results, concerning both mixtures of standards and actual samples. Results in Table 2 are only approximate because the apparently simple components often correspond to more or less complex mixtures. 
As seen in Table 1, the silica gel column achieves the perfect separation of aldrin from heptachlor expoxide, of $p, p^{\prime}-D D E$ from dieldrin and virtually, of o, $p^{\prime}$-DDT from $p, p^{\prime}$ -DDD. It helps distinguish p, $\mathbf{p}^{\prime}$-DDD from one endrin isomer, since most of the former gathers in the 9-14 fraction and none of the latter.

Silica gel chromatography also assists in establishing the presence of $\alpha$-BHC: a small part of it elutes in the last hexane fraction while the bulk elutes in the first $20 \%$ ether fraction. Generally, the distribution of a chemical over the various fractions contributes much to its identification; it may also prove that the substance does not originate from the sample, but from impurities in the solvents, materials or vessels used.

Table 1 shows also that the PCBs can interfere only slightly with $\mathrm{p}, \mathrm{p}$-DDT, very little with p,p-DDD and $\alpha$-BHC and not at all with $\gamma-\mathrm{BHC}$, heptachlor epoxide, dieldrin and endrin. Table 2 indicates that the components 11 and $12(r=0.97,1.05)$ and 9 and 10 $(r=0.76,0.88)$ have nearly the same retention times as p,p'-DDT (1.00) and o,p'-DDT (0.81) respectively but very different elution curves so that they do not cause any serious problem. On the contrary, the components $1(r=0.30), 2$ and $3(0.34,0.36)$ and 6 (0.61) are distributed over the hexane fractions more or less like heptachlor $(r=0.28)$, aldrin (0.35) and p,p'-DDE (0.61) respectively. Hence, a real difficulty seems to exist in the case of these three analytes, especially p,p'-DDE, because component 6 , as a rule, gives a peak respectively about 3,5 and 8 times higher than components 1,2 and 3 . In practice, however, these interferences mean only less satisfactory accuracy and detection limit; for the ratios of the PCBs components to one another in the samples do not differ greatly from those in either Aroclor 1254 or Aroclor 1260, or exhibit a slight trend in relation to the retention time.

Picer and Ahal (1978) and Contardi et al (1983) observed that silica gel with very small pores (4nm), such as Merck Kieselgel 40 70-230 mesh ASTM, greatly improves the separation of $p, p^{\prime}-D D E$ from PCBs. However, the contaminants present in natural biota usually include a few compounds other than those in the commercial mixtures used by the above workers (the former Aroclor 1254, the latter Fenclor 54 and Fenclor 64). In consequence, some uncertainty still impairs the determination of $p, p^{\prime}$-DDE, besides that of aldrin and heptachlor. A reliable solution consists of repeating the analysis on the gas chromatograph after chemically altering the three constituents, to remove the peaks they give, as described later.

\section{Detector temperature.}

The temperature of the ${ }^{63} \mathrm{Ni}$ electron capture detector greatly affects the performance of the gas chromatograph. Too low a temperature, besides diminishing the response, induces rapid contamination of the detector by the high-boiling compounds present in the column, as well as in the injected sample, despite its pretreatment. The ensuing sensitivity drop brings about a non-linear response, unless the polarising voltage is adequately raised. But carrying out such adjustments at frequent intervals results in time loss and poor accuracy. Excessive temperature has an even worse effect: it destroys part of the organochlorines, so that, at low concentrations, there is no response.

In consequence, the analyst must select the highest temperature that, at the correct polarizing voltage (the one producing $92 \%$ of the maximal background signal), still secures linear response at very low concentrations. A simple, fast and reliable way of checking both the sensitivity and the linearity after each sample elution is to inject the rapidly eluted mixed BHCs twice, but in different amounts: for instance $4 \mu \mathrm{l}$ of a $5 \mu \mathrm{g} / 1$ 
solution at first, then only $2 \mu \mathrm{l}$. The second time, both the tall and short peaks should be reduced in the same proportion, but not necessarily by half, owing to systematic errors. A more precise comparison requires injecting consecutively the same volume of two solutions of different concentrations: $4 \mu \mathrm{l}$ of 5 and $2.5 \mu \mathrm{g} / 1$, for instance. Whatever the prodcedure, if the ratios of the short peaks are greater than those of the tall ones, the temperature needs reducing.

Since various impurities, which may be labile or fixed, always exist in the sample, non-volatile organic matter and carbon particles slowly accumulate around the injection point in the gas chromatograph. These deposits have the property of altering certain chlorinated hydrocarbons. In particular, $p, p^{\prime}-D D T$ is partly converted into $0, p^{\prime}$ DDT, p, $p^{\prime}$-DDE and p, $p^{\prime}$-DDD; endrin gives two isomers. Hence, the chromatogram of the $p, p^{\prime}$-DDT standard or that of the endrin should be watched. After a few weeks of operation, new peaks may appear, or small ones may grow significantly bigger. In this case, 2 or $3 \mathrm{~cm}$ of the packing of the column should be removed and replaced with fresh material, or, if this is not available, with glass wool previously rinsed with hexane and heated at $180^{\circ}$ for two hours.

\section{Purification of the silica gel.}

Silica gel for chromatography contains chlorinated hydrocarbons, mainly PCBs. To remove them, Holden and Marsden (1969) washed it on a Buchner funnel with hot water and then with diethylether. However, this procedure does not satisfactorily achieve its purpose, even when repeated once or twice. Duinker and Hillebrand (1978) rinsed the oxide inside the column with dichloromethane, followed by $n$-hexane. But the choice of a chlorinated solvent to eliminate the last traces of organochlorines is not recommended.

The authors attempted to purify the material by keeping it for a few days at $180^{\circ}$ in a current of air, or at $150^{\circ}$ in vacuo. Having failed, they tried to clean the packed column with $20 \%$ diethylether in hexane, then hexane, to remove the ether, applying gentle suction to speed up the operation. Oddly enough, every time, during the subsequent normal elution with hexane, though the first few $\mathrm{ml}$ were absolutely pure, the following ones exhibited large quantities of PCBs. This baffling phenomenon led eventually to the hypothesis that the compounds absorbed by the silica gel in relatively great amounts, require a considerable time to be released from it. Indeed, the same technique, when carried out with very tardy flow and ameliorated by total immersion of the column in hexane for one or two days, proved ideal.

Addition of water to silica gel.

According to the plate theory and as confirmed by experiment, a solid phase adsorbing more strongly the analytes achieves better results. However, the consequent larger elution volumes mean delay and the necessity for concentrating huge amounts of liquid, with the attending risk of both partial loss of the organochlorines and contamination by the impurities in the solvent. Furthermore, the equilibrium between the phases, never perfect, becomes even more unsatisfactory, as it requires excessive time to be reached.

Brown and Satsmadjis (1961), trying to separate quickly and in the cold the gaseous hydrocarbons in city gas, on a column packed with the Zeolite Decalso Y and some length of alumina, discovered that they could fulfil their purpose by keeping the carbon dioxide carrier gas slightly humid. The presence of moisture also greatly reduced the tailing of carbon monoxide on the large activated charcoal column used for separating the permanent gases. 


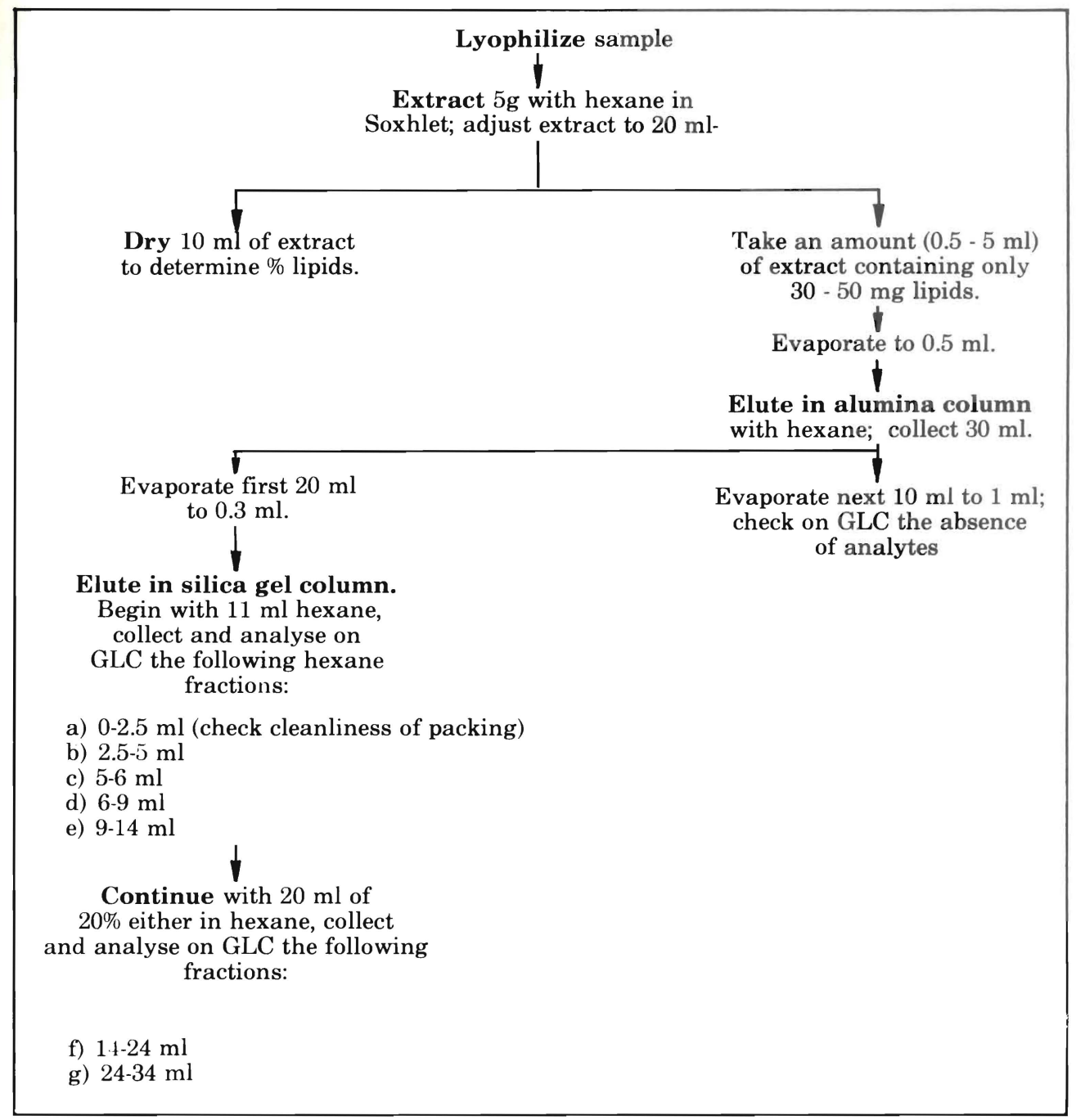

Fig. 1 Procedure for the analysis of marine organsims. 
Similarly the addition of a suitable amount of water to silica gel reduces its adsorbing power and enables the chlorinated hydrocarbons to elute faster and separate better, Prolonged contact of hexane with the material enhances this beneficial effect.

\section{Diameter of the silica gel column.}

When the sample to be eluted contains substances in concentrations so small that they cannot alter the adsorbing properties of the packing, a large bore does not elevate the efficiency of a chromatographic column. On the contrary, it produces channelling, augments the volume of eluate (in direct proportion to the area of cross-section) and since for various reasons, the wider passage does tend to increase the speed of the solvent, the equilibrium between phases has less time to take place.

In consequence, a narrow column achieves a better separation of the analytes. Also, by reducing the bulk of the fractions and the filling, the risk of contamination from the solvents and the solid phase is diminished. However, too small a diameter may induce flow stoppage. The solvents, especially ether, slowly penetrate inside the pores of the silica gel particles and the displaced air, trapped there, forms bubbles preventing or retarding the passage of liquid. It is to be noted that the thorough removal of gas from the contents of the column, achieved by the proposed conditioning of it, greatly improves the exchange between phases.

\section{Loss of the analytes}

During the pretreatment of the hexane extract, a small fraction of the constituents to be determined may remain in the lipids, the alumina and the silica gel. By reducing the solution deposited on top of the alumina column to a small volume, the undersired substances are better eliminated, but their greater concentration in the upper layer of the packing increases the risk of loss of the organochlorines. Also, a large amount of dry alumina, while improving the clean-up, augments the quantity of analytes not entirely washed off, because of the poor exchange between phases. Hence, the described procedure, which takes into account all these factors, should be strictly adhered to. Note that the conditioning of the silica gel column, besides its other advantages, ensures a practically complete recovery of the constituents.

Concentration of the solutions constitutes another major cause of loss of chlorinated hydrocarbons. The solvent vapours always contain a certain proportion of them, which, at equal content in the liquid phase, diminishes with the temperature. In consequence, the solvents should be evaporated at as low a temperature as possible. On no account should the solution be allowed to dry, even without heating or blowing, because the analytes would quickly disappear.

\section{Method}

Fig. 1 shows the main details of the procedure which has been applied extensively by Satsmadjis and Gabrieldes (1977, 1979, 1983), Satsmadjis and Voutsinou - Taliadouri (1983), and Voutsinou - Taliadouri and Satsmadjis (1983) for the anlysis of marine organisms.

\section{Results and Discussion}

As stressed already, the presence of the undesired substances in the sample injected into the gas chromatograph affects adversely the column and detector of the instrument; also, despite the clean-up on alumina and the fractionation on silica gel, 
some interference still occurs. In consequence, the precision and accuracy of the determination depend largely on the sample, mainly on the ratio of the level of the chlorinated hydrocarbon to that of both the non-removable impurities damaging the gas chromatograph and the interfering compounds, be they analyates or not. Hence, studies on synthetic mixtures or spiked samples help estimate loss and contamination due to the procedure, but not other systematic errors, or reproducibility in actual analyses.

The authors participated in three intercalibration exercises. These demonstrated that the majority of the results were greatly affected by at least some of the cardinal sources of error the present method warns against: contamiantion of the solvents, the thimble and the materials; loss by rapid concentration or evaporation to dryness; and Table 3 Intercalibration Exercise (Concentrations in $\mu \mathrm{g} / \mathrm{kg}$ )

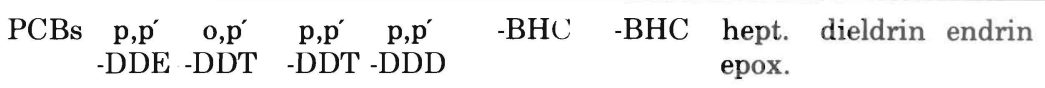

All

No of reported values

Mean

High

$\begin{array}{rrrr}14 & 24 & 8 & 22 \\ 310 & 110 & 48 & 76\end{array}$

19

$10 \quad 21$

$21-14$

$43 \quad 10$

22

$-\quad 15$

Low

56

730

$41 \quad 16$

Coeff. of

variation

$50 \quad 30$

$12 \quad 2.5$

133

66

139

- 52

Standard error $\%$

$\begin{array}{llll}55 & 130 & 100 & 59\end{array}$

$63 \quad 200$

140

$-$

0.5

\section{Best}

laboratories

No of reported values

Mean, $m$

$\begin{array}{rrrr}5 & 7 & 1 & 7 \\ 410 & 83 & 31 & 66 \\ 485 & 150 & - & 109 \\ 190 & 40 & - & 11\end{array}$

6
39
47
29

2
2.5
2.8
2.1

6

$-\quad 87$

High

Low

Coeff. of

variation

Standard error \%

$$
29 \quad 40 \quad-\quad 48
$$

1920

$8 \quad 14$

$\begin{array}{ccc}9.7 & - & 12 \\ 11 & - & 20 \\ 7.5 & - & 3 \\ 13 & - & 78 \\ 5 & - & 39\end{array}$

\section{Authors}

No of

\begin{tabular}{|c|c|c|c|c|c|c|c|c|c|c|}
\hline determinations & 5 & 5 & 5 & 5 & 5 & 5 & 5 & 5 & 5 & 5 \\
\hline Mean, $m^{\prime}$ & 430 & 65 & 24 & 70 & 44 & 2.8 & 11.9 & 0.5 & 10.3 & 3.5 \\
\hline High & 550 & 73 & 28 & 82 & 48 & 3.8 & 14.5 & 0.8 & 12.1 & .3 \\
\hline Low & 285 & 54 & 21 & 61 & 41 & 1.4 & 9.0 & 0.3 & 8.5 & 2.8 \\
\hline $\begin{array}{l}\text { Coeff. } \\
\text { of variation }\end{array}$ & 24 & 12 & 13 & 11 & 8 & 30 & 18 & 40 & 15 & 17 \\
\hline Standard error $\%$ & 11 & 5 & 6 & 5 & 4 & 13 & 8 & 18 & 7 & 8 \\
\hline $100\left(m^{\prime}-m\right) / \mathrm{m}$ & 5 & -22 & -23 & 6 & 13 & 12 & 23 & - & -14 & \\
\hline
\end{tabular}

* in a sample of muscle of Mullus barbatus (conc. fresh weight) 
insufficient separation prior to injection into the gas chromatograph. In one of these exercises (Villeneuve et al 1976) concerning dry oyster tissue homogenate, with 26 participants, the means of the determinations by seven laboratories, chosen for their reliability, had coefficients of variation ranging from 13 to 78 (Table 3). This is quite high, considering that the concentrations varied from $2.5 \mu \mathrm{g} / \mathrm{kg}$ for $\mathrm{BHC}$ to $410 \mu \mathrm{g} / \mathrm{kg}$ for the PCBs. But more alarming still is the fact that o,p-DDT was reported by only 1 participant, $\alpha$-BHC by 2 , dieldrin by 4 , PCBs by $5, \gamma-B H C$ and p,p'-DDD by 6 . This astounding disagreement on even the qualitative analysis proves the absolute necessity for carrying out the proposed fractionation on the silica gel.

Table 3 indicates that the authors' means do not differ significantly from those of the seven laboratories (5 to 23\%). As expected, the coefficient of variation, $v$, rises when the concentration decreases: it is only 8 to 13 for p, $\mathrm{p}^{\prime}$-DDD, p, $\mathrm{p}^{\prime}$-DDT, p, $\mathrm{p}^{\prime}$-DDE and $\mathrm{o}, \mathrm{p}^{\prime}$-DDT, but 15 to 40 in the case of dieldrin, endrin, $\alpha$-BHC, $\gamma-\mathrm{BHC}$ and heptachlor epoxide. The ill-defined and complex PCBs constitute an exception, with $v=24$.

\section{ACKNOWLEDGEMENTS}

Indebtness is expressed to Fanny Voutsinou-Taliadouri and Gabriel Gabrielides for their useful criticism.

\section{REFERENCES}

Brown, G.M. and Satsmadjis, J. (1961) Gas chromatography. Coke and Gas 23, 261:48-54.

Contardi, V.; Capelli, R.; Zanicchi, G. and Drago M. (1983) Chromatographic separation of chlorinated hydrocarbons using columns of silica gel of varying degrees of porosity and activation. Analyst 108: 510-524.

Duinker, J.C. and Hillebrand, M.T.J. (1978) Minimizing blank values in chlorinated hydrocarbon analysis. J. Chromatog. 150: 195-199.

Holden, A.V. (1973) Mercury and organo-chlorine residue analysis of fish and aquatic mammals. Pesticide Sci. 4: 399-408.

Holden, A.V. and Marsden, K. (1969) Single-stage clean-up of animal tissue extracts for organochlorine residue analysis. J. Chromatog. 44: 481-492.

Picer, M. and Ahel, M. (1978) Separation of chlorinated biphenyls from DDT and its analogues on a miniature silica gel column. J. Chromatog. 150: 119-127.

Satsmadjis, J. and Gabrielides, G.P. (1977) Chlorinated hydrocarbons in striped mullet. Thalassographica 1: 151-154.

Satsmadjis, J. and Gabrielides, G.P. (1979) Observations on the concentration levels of chlorinated hydrocarbons in a Mediterranean fish. Mar. Poll. Bull. 10: 109-111.

Satsmadjis, J. and Gabrielides, G.P. (1983) Organo-chlorines in mussel and shrimp from the Saronikos Gulf (Greece). Mar. Poll. Bull. 14: 356-358.

Satsmadjis, J. and Voutsinou-Taliadouri, F. (1983) Mytilus galloprovincialis and Parapenaeus longirostris as bioindicators of heavy metals and organo-chlorine pollution. Mar. Biol. 76: 115-124.

Villeneuve, J.P.; Marchand, M.; Elder, D.; Fowler, S.W.; Larosa, J.; Duursma, E.K.; Vas, D. and Parsi, P. (1976). Intercalibration measurements for non-nuclear pollutants. Organo-chlorine compounds: progress and results to date. In: International Atomic Energy Agency (editors) Activities of the international laboratory of marine radioactivity, Vienna, pp. 99-106.

Voutsinou-Taliadouri, F. and Satsmadjis, J. (1982) Influence of metropolitan waste on the concentration of chlorinated hydrocarbons and metals in striped mullet. Mar. Poll. Bull. 13: 266-269. 